\title{
A self-regulated Internet community
}

\author{
Dimitrios Vogiatzis and Symeon Retalis \\ National Technical University of Athens, \\ Department of Electrical and Computer Engineering, \\ 15780 Zographou Campus, Athens, Greece \\ Email:dimitrv@central.ntua.gr, retal@softlab.ntua.gr
}

\section{INTRODUCTION}

It would be a commonplace remark to note that the Internet is growing fast; nevertheless, we feel compelled to report that the Internet doubles in size every 1215 months. There were roughly 12 million hosts in July, 1996 [1]. Whereas it is difficult to tell the exact number of actual users, we know that they are scattered worldwide.

In a sense, the Internet is a community. But, unlike a traditional community, it cannot be located on the map unless we consider cyberspace as its natural site. This community only produces and consumes information. The old questions about politics emerge again seeking a new context on the Internet. In particular, who is in charge? Why should it be that way? How is power exercised? How are vague ideas about the state of things to be consolidated in rules, ethics, or laws? We shall attempt to answer these queries in the context of the current and prospective state of the Internet.

At a rather abstract level, the central idea we are trying to convey is that of freedom of expression, which has been an essential ingredient of democratic countries. That is, being free to publish in various forms (via text, sound, video, etc.) any idea, irrespective of the cultural make-up of the potential recipients. We are also advocating tolerance, one of the fundamental ideas of the Declaration of Human Rights of the French Revolution of 1789. Furthermore, we stand unfavourably against unfair advantage gained by plagiarism. In the next paragraphs, we will mention a particular way in which these ideas can be consolidated. In any case, we will be talking about netizens (citizens on the network) and their political rights within the Internet community. The following terms will be used interchangeably: the net and the Internet. 
There are currently societies and consortiums that deal with different aspects of the Internet. The W3C consortium [2] mostly deals with the standardization of the world wide web, but also has a societal component which strives to preserve freedom of expression on the Internet. The purposes of the Internet Society [3] range from hardware to assisting developing countries maintain and evolve their Internet structure. On the other hand, the Web Society [4] is concerned with political, legal, and societal issues as well as with tools to make information retrieval easier.

We are not proposing a novel community, but rather a set of principles in the light of which existing or future societies can be evaluated as far as the free flow of information is concerned. Thus, we will not discuss hardware or related protocols.

Figure : Internet growth (source: Network Wizards http://www.nw.com)

\section{Internet Hosts - Overall Trend}

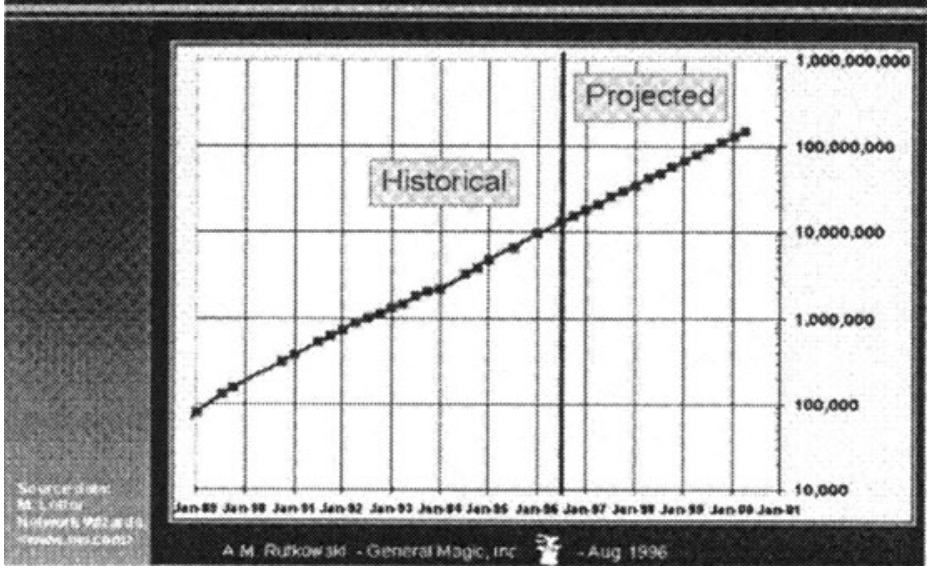

\section{THE CURRENT STATE OF POLITICS ON THE INTERNET}

The Internet is interesting not only as a massive global network but also as an example of something that continuously evolves with no apparent designer in charge. At the beginning, the Internet was used mostly by academics for information retrieval and exchange of information resources (hypertext documents). Nowadays, it is used not only for collaboration, exchange of know how, expertise and experiences (such as ftp, email, newsgroups, and conferencing systems) but for instruction delivery (open and distance learning programmes), for commercial reasons (shopping, advertisements of products) as well as for entertainment (realtime audio, video, multimedia games, and so on). So when we say that the Internet is changing, we not only mean that it is growing - nobody knows the 
number of netizens - but also that its use has changed and the software applications that increase its potential are constantly being developed.

We will try to depict, through a few specific cases, some of the issues that have arisen on the Internet lately, with the purpose of attesting that we have not yet understood how to live in the Internet community. Mostly, we are feeling our way into it, blundering about. As a result, topics, discussion cases, and questions arise, such as computer crime (hackers, violation of national security), protection of intellectual property (copyright issues), and freedom of expression.

In December 1995, CompuServe (a worldwide Internet service provider) banned access (although temporarily) to certain newsgroups following the orders of the German authorities about obscene material. CompuServe followed a decision of only local importance and applied it to its servers worldwide for technical reasons.

In January 1996, the German phone company, Deutsche Telecom, blocked users of its network from accessing the email address of Ernst Zuendel in Canada because of the neo-Nazi context of his web pages. Soon mirror sites were created which enabled the outflanking of the restrictions imposed.

China is following a rather strict policy as far as the Internet is concerned. From now on in China, all computer networks are subject to the authority of the State Council. The ministry of posts and telecommunications will provide approved communication channels for Internet access. The purpose of this policy is to impose censorship on material of a political or a pornographic nature. However, this target can be achieved without compromising the free expression of ideas. There is software which can scan and censor unwanted words that can be employed by netizens according to their own values and ethics [5].

The aforementioned cases also bring to light certain issues. First, there is a confusion between Internet service providers and content providers as the case of CompuServe and Zuendel demonstrates. Second, it seems that in times of globalization, we still face certain issues at a local level. Third, it appears that occasionally the restriction of pornography is a pretext for political control as the new legislation in China shows. Last but not least, netizens are nowhere to be found. Most, if not all, of the policies applied so far have been decided by governmental agencies, organizations or Internet service providers. It is clear that netizens are not represented on any of these bodies.

\section{THE BUILDING BLOCKS OF DEMOCRACY ON THE INTERNET}

Netizens are the active members of the Internet, in the sense that they receive and disseminate information by means of various Internet services like email, newsgroups, web pages, Internet Relay Chat (IRC) etc. Thus, it is only natural for netizens to participate in decision-making as far as the net is concerned. But, before going any further, we have to discuss briefly the identity of netizens. Currently, there are individual users, and there are various conglomerations ranging from enterprises and educational establishments to governmental agencies. Ideally, netizens should be the only body to run the net. In other words, we are talking about a community that is self-regulated. This has been largely the case so far, but this status has to be preserved in an era of big changes. 
At this point, we should be more specific about the identity of netizens. In ordinary societies, it is the adults - practically those aged at least 18 years old who have political rights. The question is not whether there should be the same age threshold on the net, but whether there should be an age limit in principle. We believe that there should be a hierarchy of presuppositions for participation in the three bodies proposed below, through which power is exercised, otherwise the whole process is reduced to ridicule. Age should be one of the criteria for participating in decision-making; for instance, it would certainly be awkward for children to decide on the infringement of a particular code of ethics on the net. On the other hand, traditional societies do not put much faith in adolescents; however, teenagers tend to be much more computer literate than grown-ups. Therefore, adolescents cannot and should not be excluded from participating in some of these bodies. After all, computer literacy is one of presuppositions, the other is a level of political maturity.

Another subject of concern is the difference in political rights within the net, between individual users and corporations, educational establishments, or societies of various sorts, like the W3C Consortium or the Internet Society. We believe that such societies should only act as consultative committees to executive, legislative or judiciary bodies. Their role is most valuable because of the experience these societies have accumulated.

Netizens exercise power directly on all matters of concern. That is, they participate voluntarily in debates and they finally reach a consensus. In order to clarify the way political issues are handled, we will examine them in the light of these three political bodies which also draw the distinction among the political powers in democratic societies.

\section{Executive body}

The net is conceived as an autonomous community. The most important decisions concerning the affairs of the net are to be taken within the net and by all members who qualify as netizens. The word executive is somewhat illusive. In the real world, a government does not execute orders; on the contrary, it is the primary source of power. Therefore, this is probably the most influential body on the net. The members vote on all subjects that concern the net, irrespective of their exact geographical location. Normally, we would expect the existence of many executive bodies, each dealing with a specific subject.

We are already experiencing a limited form of executive power. The creation of a novel newsgroup involves voting. A more evident example is the display of a blue banner on black web pages; this has expressed the grievances of netizens in relation to the United States' Communications Decency Act. However, we have also witnessed the dark side of authority by system administrators who may cast many votes. 


\section{Legislative body}

Netizens are to create a Bill of Rights, that is, some form of constitution for the net which will regulate information flow and form the basis of the law-making process. The rights and the responsibilities of netizens are the core activity of this body. Normally, we endorse the principle of free information access and free expression within the net. Obviously, totally unregulated free access to any source of information might not prove to serve the basic function of the net. For instance, invasion of privacy or access and disclosure of corporate data are not considered as cases of free access.

We have witnessed many cases where the rights of netizens are clearly compromised. For instance, free access to North Korean databases is forbidden for South Koreans [6]. Thus, a definite bill of rights will help us towards setting a framework for the activities of the netizen.

There have been many excellent propositions that have defined a scheme for the state of things on the net. We could cite the Electronic Rights and Ethics [7] or the aims of the Web Society [4]. The task of a legislative body would be to debate new acts of law and finally to vote for or against them.

\section{Judiciary body}

Traditionally, the role of courts of law has been to detect infringement of the resolutions of the legislative body. The judiciary is usually staffed by professionals (judges, for instance). On the net, the first issue to be addressed is the make-up of the members of this body. We endorse the participation of every netizen in this body. However, as the network becomes more and more complex, with the adoption of business acts, certain issues might become too complicated and therefore demand a certain professionalism. That is, it might prove that netizens without special training might not be able to handle appropriately certain matters.

Let us see some of the issues that might arise, for which the judiciary body is responsible: copyright infringement, unauthorized access to confidential information (by hackers, for instance), and invasion of privacy are some of the issues that are dealt with in ordinary courts outside the net. It is not commonplace to talk about such subjects on the net, much less in the context of a formal body, and yet these subjects mainly concern the net.

A precise definition of the responsibilities of this body is somewhat problematic. An ordinary court of law pronounces sentences; we can hardly foretell the nature of those sentences within the net. Perhaps, they could range from a simple recommendation to expulsion from the net for a certain period.

The three bodies through which power is exercised (executive, judiciary, legislative) are mentioned in Aristotle's works, and were reinvented by Montesquieu to become the core of the first French constitution after the revolution of 1789 . However liberal these bodies may seem, one might consider them as a barrier towards free expression especially if we take into account the present anarchistic nature of the Internet; but this is illusory. Every netizen is allowed to participate in this three-ply structure; that is, nobody is excluded from power. Second, we advocate direct involvement, that is, without representatives. Third, 
we have already mentioned that the Internet is changing. Commercial interests and governmental agencies are influencing the net profoundly. There is no time available to be uninterested in the process of forming the future state of the Internet. Whether these structures will preserve the free exchange of information on the Internet depends on netizens getting involved. Incidentally, it is interesting to cite an ancient historian:

'... and our ordinary citizens, though occupied with the pursuits of industry, are still fair judges of public matters; for, unlike any other nation, regarding him who takes no part in these duties not as unambiguous but as useless ...' Thucydides, The History of the Peloponnesian War, Funeral Oration of Pericles, circa $431 \mathrm{BC}$.

There are also certain issues that have be dealt with from a practical point of view. Of particular importance is the subject of netizen authentication and privacy when voting. Fortunately, the technology is ripe enough to meet the aforementioned demands; for example a public key cryptography like RSA [8] can fulfil our needs.

Naturally, there must be a means of communication between the netizens when exercising their political powers. Newsgroups or mailing lists can play such a role; nevertheless a major problem lies in the sheer volume of information that is communicated. For instance, a major subject that concerns the legislative body might involve reading a great number of electronic messages. After all, membership of the legislative body might be in the order of hundreds or even thousand of netizens. Obviously, we cannot expect an individual to be able to consume that amount of information. Some form of computer aid is required which would summarize the information involved, thus vastly reducing the information overload.

We have mentioned that all netizens are eligible to participate in the executive, legislative, judiciary and executive bodies. However, it is undesirable or even unfeasible for all of them to participate unconditionally in the exercise of power. The purpose of the self-regulated Internet community would be best served by large committees which would staff the three bodies for a limited time span. For instance, when there is a breach of a particular law, a court could be formed to deal with it, then the court could vanish into thin air [9]. Thus, the limited time span committees serve a two-fold purpose: they entice netizens to behave in a responsible manner and the very fact of their limited time span facilitates the participation of most netizens.

Furthermore, we might not totally exclude the concept of electing representatives especially for domains of minor importance demanding a certain level of know how. For example, an elected consultative committee for the judiciary body would be very helpful.

\section{CONCLUDING REMARKS}

Netizens will encounter more and more often a confrontation between their desire to be autonomous, in the sense of self-governed, and some of the governments around the world. However, we believe that netizens constitute a very influential lobby on a worldwide basis. In fact, just as certain rights are (or should be) given to each 
netizen, each one should be held accountable for his or her actions. Each netizen, as a member of the Internet community, is responsible or obliged to all other netizens to respect and value the rights of privacy of all; to recognize and respect the diversity of the population and opinion in the community; to comply with legal restrictions regarding the use of information resources; to recognize that all members share information and technology resources; and to refrain from acts that waste resources or prevent others from using them.

The problems of running the net for the benefit of its netizens have not been solved here. In this paper, we have tried to propose a set of principles for evaluating the levels of democracy in the Internet community. We believe that it is up to the netizens to be more active in finding such an answer.

\section{REFERENCES}

[1] Net Wizards, http://www.nw.com/zone/WWW-9607/report.html

[2] http://www.w3.org/pub/WWW/

[3] http://info.isoc.org/

[4] http://aace.virgina.edu/aace/websoc/

[5] Bhorn M, Chen Y, Y: The World-Wide Market: Living with the Realities of Censorship on the Internet. First World Conference of the Web Society. San Francisco, CA, October 1996.

[6] Fox R., News Track, Communications of the ACM, September 1996, 96.

[7] Electronic Rights and Ethics, http://www.zip.com.au/ pete/ere.html

[8] Rivest, R.L., A. Shamir, and L. Adleman. A Method for Obtaining Digital Signatures and PublicKey Cryptosystems. Communications of the ACM. February 1978, 120-126.

[9] Ethics and Law on the Electronic Frontier, http://www-swiss.ai.mit.edu/6095/index.html 